\title{
Influence of solar and geomagnetic activity in Gymnodinium catenatum (Dinophyceae) cultures
}

\author{
Paulo Vale \\ The Portuguese Sea and Atmosphere Institute, I. P. (IPMA, IP), Sea and Marine Resources Department (DMRM), Avenida \\ de Brasília s/n, 1449-006 Lisbon, Portugal
}

\begin{abstract}
Laboratory cultures of the paralytic shellfish poisoning producing microalga Gymnodinium catenatum were subjected to a hypo-osmotic shock and changes in cell concentration were observed in two separate experiments of 8 and 24 hours duration, respectively. The increase in geomagnetic activity (GMA), radio and X-ray fluxes and solar X-ray flares were negatively correlated with cell numbers. Cell losses were observed in the short experiment, but not in the longest one. GMA action was related to the course of the experimental period, while electromagnetic radiation (EMR) was only significantly related when the previous hours before the experiments were considered. The differential action windows might be indicative of two differential disruptive mechanisms: EMR might act on DNA synthesis and mitosis phases of the cell cycle (taking place in the dark period) and GMA might be more disruptive at the end of mytosis or cytokinesis phases taking place in the light period. Formation of long chains ( $>4$ cells/chain) was reduced with salinity and with temperatures above $27^{\circ} \mathrm{C}$ but increased with EMR and GMA, particularly when grown at the highest temperatures recorded during the study period $\left(\geq 28^{\circ} \mathrm{C}\right)$.
\end{abstract}

Key words: Gymnodinium catenatum - Geomagnetic activity - Solar cycle - X-ray flux - Cell division - Chain formation - Chronoastrobiology

\section{Introduction}

Gymnodinium catenatum Graham is a marine athecate chainforming dinoflagellate. Along with a few other dinoflagellates and cyanobacteria, it is a known producer of paralytic shellfish poisoning toxins (PSTs) (Orr et al. 2013). Its bloom can lead to contamination of bivalve mollusks with PSTs, which in turn originate the human acute neurological syndrome, known as PSP (paralytic shellfish poisoning) (FAO 2004).

For protection of human consumer's, natural shellfish beds and aquaculture sites are closed to harvest during

Electronic supplementary material. The online version of this article (doi: 10.4149/gpb_2016038) contains supplementary material, which is available to authorized users.

Correspondence to: Paulo Vale, Instituto Português do Mar e da Atmosfera, I.P. (IPMA), Departamento do Mar e Recursos Marinhos (DMRM), Avenida de Brasília s/n, 1449-006 Lisbon, Portugal E-mail: pvale@ipma.pt events of harmful algal blooms (HABs) such as this one, which in turn reduces the income of related professional activities (Rodríguez et al. 2011). This draws a strong attention and interest in the study of HAB phenomena, but not always $\mathrm{HAB}$ recurrence is easily understood. This is the case with occurrence of Gymnodinium catenatum, the main PST producing microalgae at the northwest Atlantic Iberian coast: it shows a large intra-annual variability, but a contrasting more predictable summer to autumnal seasonality (Pazos et al. 2006; Vale et al. 2008; Pitcher et al. 2010). The seasonal trend of high severity blooms follows the reduction in solar exposition from the summer towards the winter solstice (Vale 2013), typical from mid to high latitude zones. This could be due to reduction in deleterious effects from excessive ultraviolet (UV) radiation. This microalga requires strong protection in the UV range, particularly in the near-UVA, which is provided by the mycosporine-like amino acids (MAAs) (Jeffrey et al. 1999; Vale 2015a, 2015b). These photoprotector molecules are all nitrogen-containing compounds (Sinha et al. 1998), but in turn nitrogen is generally a limiting 
nutrient in oceanic seawater (Moore et al. 2013), thus probably restricting blooming to seasons with less UV exposure. G. catenatum growth is also limited under low temperatures, generally at $14^{\circ} \mathrm{C}$ or below for Iberian strains (Bravo and Anderson 1994). Water temperature is higher during summer to autumn and low temperatures in December (mean below $14.5^{\circ} \mathrm{C}$ ) indeed restrict blooms as these generally terminate past November, although shellfish contamination still remains for another month or more (Vale et al. 2008; Vale 2013).

However, these cycling parameters fail to explain why large blooms sometimes can take place in successive years or can be absent by contrast for almost a decade (Pazos et al. 2006; Vale et al. 2008). Recently, Vale (2013) hypothesized this intra-annual variability was related to solar and geomagnetic activity (S-GMA). A statistical study of data gathered from PSTs accumulated in mussels from the northwest of Portugal since 1986, showed the accumulation of PSTs originating from G. catenatum was significantly associated with low levels of solar activity (sunspot number and solar radio flux in the microwave range) and also low levels of the Aa geomagnetic index (a measure of geomagnetic activity).

However, PST's levels derived from G. catenatum in bivalves from the Portuguese south coast were not statistically associated with low sunspot number. A statistically significant association with low Aa geomagnetic index also was not achieved, due to the low number of occurrences, although the 25-75 percentile was restricted to low $\mathrm{Aa}$ indexes in a similar way to that found for mussels from the NW coast (Vale 2014).

The influence of geomagnetic activity seems a common denominator for large blooms to take place at both the NW and south coasts. When we compare maximal monthly occurrence of PSTs in mussels from the NW coast with the environmental parameters discussed above, geomagnetic index emerges as more relevant than seawater temperature or near-UVA radiation at noon for large contaminations to take place (Fig. S1).

The influence of natural electromagnetic fields (EMFs) on a variety of living beings, such as fluctuations in geomagnetic activity, has been noted by several researchers (Héroux 1979; Bureau and Persinger 1992; Bureau et al. 1996; Izmaylov et al. 2005; Bondarenko and Evstafyev 2006; Babayev and Allahverdiyeva 2007; Galic and Persinger 2007; Hu et al. 2009; Kolesnikov et al. 2009; Krylov et al. 2013; Shaposhnikov et al. 2014), but is still largely ignored by the scientific community.

The aim of this research was to find in vitro evidence for possible effects from S-GMA in this microalga in order to better understand its natural blooms and their relation with the solar cycle. The experimental design emerged from the continuation of a previous set of experiments targeted at understanding the role of MAAs in osmoregulation (Vale 2016). It involved the introduction of a hypo-osmotic shock to G. catenatum in culture. As EMFs can alter activity of ion channels, specifically the voltage-gated calcium channels (reviewed in Pall 2013), it was initially thought that a strategy that created an ion unbalance could enhance effects derived from S-GMA.

\section{Materials and Methods}

\section{Culturing conditions}

The G. catenatum strain used in this study, IO.13.04, was from the algal library of the Instituto de Oceanografia, Lisbon University. It was originally collected offshore from the Espinho coast in September 2005 and isolated from a 2-cell chain.

A bulk culture media stock was prepared by filtering seawater collected from Cascais Bay on a $20 \mu \mathrm{m}$ sieve. Salinity was measured with a visual hand-held refractometer (Index Instruments, Ramsey, UK) adjusted with demineralized water as required, enriched with $f / 2$ nutrients, with extra $10^{-8} \mathrm{M}$ selenium and no silica (f/2+Se media). The bulk culture media was kept refrigerated in the dark. When required, aliquots were sterilized in an oven at $80^{\circ} \mathrm{C}$ for 1 hour prior to any experiments. Duran ${ }^{\circledR}$ GL45 borosilicate bottles were used for maintaining stock cultures and experiments. Bottles were capped with polystyrene Petri-dishes halves, thus allowing light to pass through vertically.

Two lighting facilities were used as described before, placed in a cool basement floor without air-conditioning, located at sea-level altitude (Vale 2015b). The halogen facility (HAL-room) consisted of overhead vertical illumination with halogen spots providing a 12:12 hour light:dark cycle. Spots supplied halogen light with a $50 \mathrm{~W}$-equivalent (OSRAM, HALOPAR ECO, 42 W, GU10 type). Distances of spots to shelf were $57 \mathrm{~cm}$. Photosynthetic active radiation (PAR) was measured at the shelf level with a Li-Cor light meter (Li-Cor, Nebraska, USA). PAR was $43 \mu \mathrm{mol} \mathrm{m} \mathrm{m}^{-2} \mathrm{~s}^{-1}$ at the centre of the spot focus. Maximal water temperature, observed at the end of the daily light period, was displayed in Fig. 1C.

The fluorescent facility (FLU-room) consisted of overhead vertical illumination with a bank of four $18 \mathrm{~W}$ Osram's cool white fluorescent tubes (590 mm, light color 840), in a 12:12 hour light:dark cycle synchronized with the HAL-room, providing a PAR of $24 \mu \mathrm{mol} \mathrm{m} \mathrm{m}^{-2} \mathrm{~s}^{-1}$. Distances of light tubes to shelf were $50 \mathrm{~cm}$. In both sets, lamps were mounted on wood frames attached on top of wooden tables for avoiding ferromagnetic material creating static magnetic fields in close proximity to the cultures.

For cell counts, triplicate 4-5 ml subsamples were taken into $10-\mathrm{ml}$ glass tubes, preserved with $40 \mu \mathrm{l}$ of Lugol's iodine 
solution (diluted 1:1 with water) and counted in 96-well micro plates $\left(4^{\star} 50 \mu \mathrm{l} / \mathrm{sample}\right)$ using a stereo microscope (model MZ7s, Leica Microsystems, Wetzlar, Germany). The number of cells per chain was recorded in all cases. Homogenization was performed by gentle hand flipping in order to preserve information of chain composition. When the coefficient of variation of triplicate tubes surpassed $15 \%$, the outlier tube was gently homogenized and counted again.
A

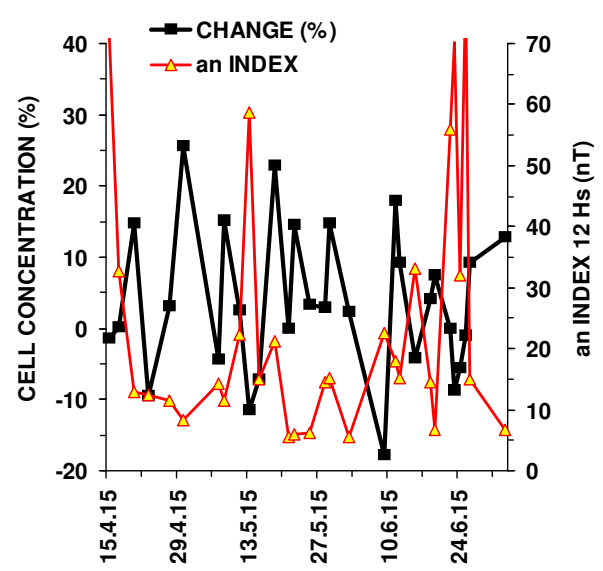

B

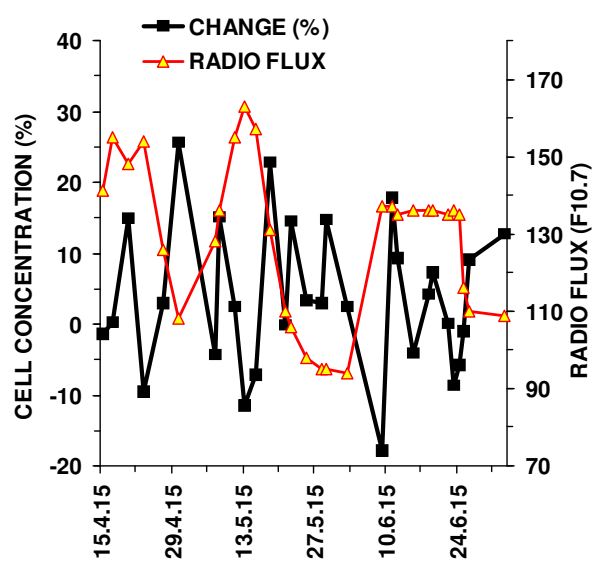

C

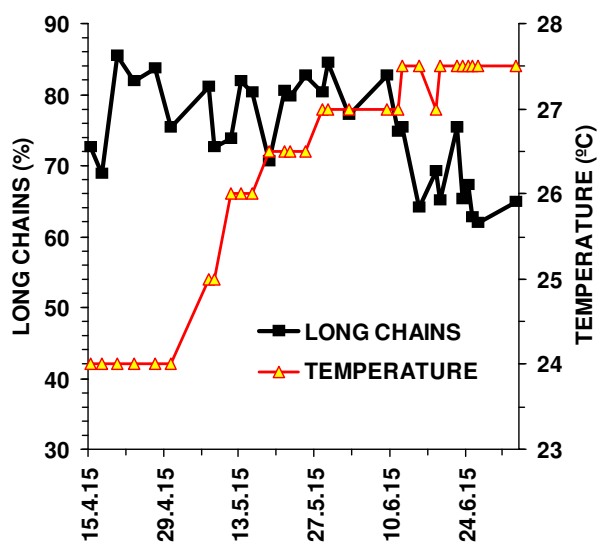

D

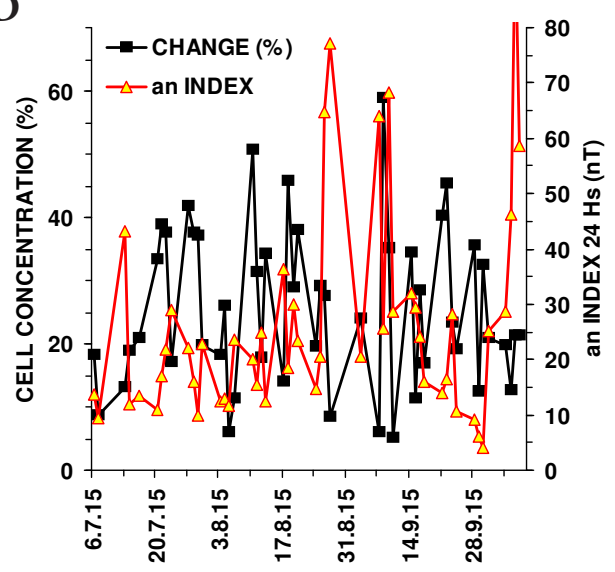

E

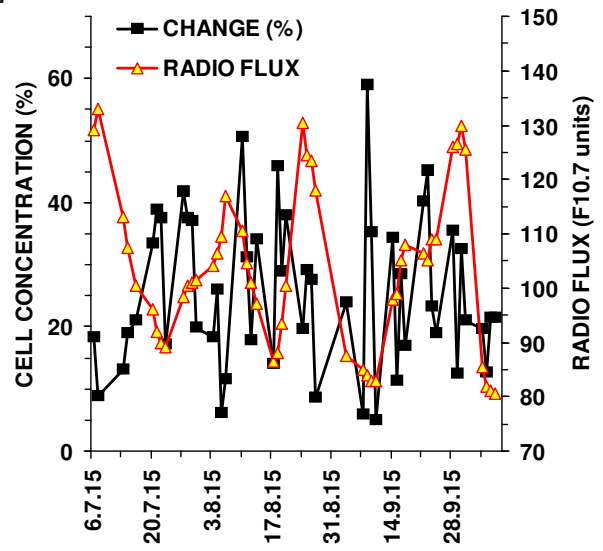

F

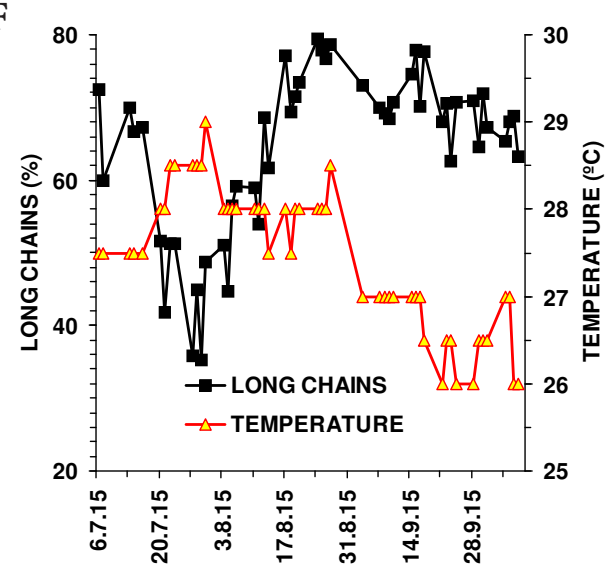

Figure 1. Changes in cell concentration in Experiments 1 (left) and 2 (right) versus mean an geomagnetic index (A and D), solar radio flux (B and E). C., F. Percentage of cells in long chain formation at the experiment start versus maximal water temperature $(n=30$ in $\mathrm{A}-\mathrm{C}$ and $n=50$ in $\mathrm{D}-\mathrm{F})$. 


\section{Standardized hypoosmotic shock experiments}

\section{Experiment 1}

Inoculate was maintained in semi-continuous culturing conditions at $33 \mathrm{psu}$ in the HAL-room in a $1000 \mathrm{ml}$ bottle (circa $950 \mathrm{ml}$ culture media). A 200-ml aliquot was taken and diluted with $35 \mathrm{ml}$ of Milli-Q water, representing a 5 psu salinity drop. Triplicate samples were collected at 0 and 8 hours: $30-\mathrm{ml}$ for MAA analysis, and 4-5 ml for cell counts (data on MAA concentration was reported in Vale 2016). Culture aliquots were left undisturbed between the start and end of the experimental period. Experiments started circa 1 hour after entering the 12hour light period. The light period started at 7 a.m. and was the same as the UTC (Coordinated Universal Time) (UTC+0). No changes were made for local summer time.

Two experiments were carried out per week. Culture media was replenished at the end of the week, representing approximately a 1:1 dilution. Inoculate was only taken again after a minimal of 3 days past media replenishment. This experiment was carried out along 8 consecutive weeks between April and June 2015. It was immediately prolonged for another 4 consecutive weeks, but no MAA analyses were performed in this second period. This required drawing less inoculate from the $1 \mathrm{l}$ bottle (only $100 \mathrm{ml}$ were diluted with $17.5 \mathrm{ml}$ of Milli-Q water) and allowed to carry out between 3 and even up to 5 experiments per week. Mean cell concentration was $2.0 \times 10^{3}$ cells $/ \mathrm{ml}$ (Fig. S6a).

Cellular concentration of MAAs was determined by HPLC with DAD detection as described in Vale (2016).

\section{Experiment 2}

Inoculate was maintained in semi-continuous culturing conditions at $35 \mathrm{psu}$ in the HAL-room in a $1000 \mathrm{ml}$ bottle (circa $950 \mathrm{ml}$ culture media). A 100-ml aliquot was taken and diluted with $17.5 \mathrm{ml}$ of Milli-Q water, representing a 5 psu salinity drop. It was then placed in the FLU room for 24 hours. For cell count triplicate $4-5 \mathrm{ml}$ samples were collected at 0 and 24 hours. Culture aliquots were left undisturbed between the start and end of the experimental period. Experiments started circa 1.5 hours after entering the 12 -hour light period (or $\approx 8: 30$ a.m. UT). This experiment was carried out along 15 consecutive weeks between July and October 2015. Experiments were initiated between Mondays and Thursdays, with cells aged 3-6 days after past week's media replenishment. Culture media was replenished every Friday morning by a 1:1 dilution. Mean cell concentration was $1.8 \times 10^{3}$ cells/ml (Fig. S6b).

\section{Geomagnetic activity}

am Geomagnetic Index values were obtained from International Service of Geomagnetic Indices (http://isgi.unistra. $\mathrm{fr} /$ ). This index is available from 1959 onwards and its purpose is to provide a characterization of global time-varying geomagnetic activity using a large set of stations representing all longitudes and possible hemispheric discrepancies. For best describing geomagnetic activity at the north hemisphere only the an Geomagnetic Index (or Northern hourly index) was used, rounded to unit $1 \mathrm{nT}$.

It is available with a time resolution of 3-hour intervals with a total of eight daily periods, and is expressed in nanoTesla (nT). The first of these periods starts daily from midnight Universal Time (UT), and subsequent periods start at 3, 6, $9,12,15,18$ and 21 hours, respectively. Here, these were designated 1 through 8 , respectively.

In Experiment 1, for increase in cell concentration, mean 24 hour an Index activity was calculated from the experiment termination backwards, covering the $6^{\text {th }}-8^{\text {th }}$ periods in day- 1 and the $1^{\text {st }}-5^{\text {th }}$ periods in day-0. In Experiment 1 , for chain formation, mean 24 hour an Index activity was calculated from the dawn backwards, covering the $3^{\text {rd }}-8^{\text {th }}$ periods in day- 1 and the $1^{\text {st }}-2^{\text {nd }}$ periods in day- 0 .

In Experiment 2, for increase in cell concentration, mean 24 hour an Index activity was calculated from the experiment termination backwards, covering the $3^{\text {rd }}-8^{\text {th }}$ periods in day- 0 and the $1^{\text {st }}-2^{\text {nd }}$ periods in day+1. In Experiment 2, for chain formation, mean 24 hour an Index activity was calculated from the dawn backwards, covering the $3^{\text {rd }}-8^{\text {th }}$ periods in day- 1 and the $1^{\text {st }}-2^{\text {nd }}$ periods in day- 0 .

\section{Solar activity}

Solar activity parameters were retrieved from NOAA's SWPC Anonymous FTP Server (http://legacy-www.swpc.noaa.gov/ $\mathrm{ftpmenu} /$ indices/old_indices.html).

Solar radio flux $(\mathrm{R})$ is measured in solar flux units $\left(\mathrm{F}_{10.7}\right.$ units), where one unit equals $10^{-22} \mathrm{Wm}^{-2} \mathrm{~nm}^{-1}$. Daily values from day-2 were used for data treatment in Experiment 1, while day-1 was used for data treatment in Experiment 2.

Soft X-ray background flux was measured by GOES15 satellite in the 100-800 pm range. Most of X-ray background flux observed during the experimental period corresponded to B-level, or $10^{-7} \mathrm{~W} / \mathrm{m}^{2}$. Flux in C-level was multiplied by 10 times for obtaining the corresponding B-level units. The number of X-ray flares was summed, only $\mathrm{C}$ and $\mathrm{M}$ classes were found during both experimental periods. In both cases daily values from day-2 were used for data treatment in Experiment 1, while day-1 was used for data treatment in Experiment 2.

\section{Remaining parameters}

Ocean temperature data for Leixões harbor (northwest Portugal) was made available from Instituto Hidrográfico, Portugal. Near-UVA $(340-400 \mathrm{~nm})$ data for parallel $39^{\circ} \mathrm{N}$ 
was determined from the solar calculator made available by Diffey (2015).

Indoors electromagnetic fields were kept to a minimum as possible. Extremely low frequency magnetic fields (from powerlines, transformers, adapters, etc) in the $10-2000 \mathrm{~Hz}$ range were kept below $<0.01 \mu \mathrm{T}$ (EMFields Professional, EMFields, UK). Average microwave fields from telecommunications in the $200-8000 \mathrm{MHz}$ range were below $1 \mu \mathrm{W} / \mathrm{m}^{2}$ in both rooms (Acoustimeter, RF Meter model AM-10, EMF fields, UK). Peak level microwave fields were below $<0.11$ $\mathrm{V} / \mathrm{m}$ in the HAL-room and $<0.04 \mathrm{~V} / \mathrm{m}$ in the FLU-room.

In order to keep $50 \mathrm{~Hz}$ electric fields to a minimum, cables were kept at a minimal distance from flasks of $15 \mathrm{~cm}$ in the HAL room and $50 \mathrm{~cm}$ in the FLU room. When using the fluorescent setting, additional sources of close artificial EMFs were the electronic ballasts. These emit in the radiofrequency range and might cover the entire kilohertz range (Kvasznicza and Elmer 2006). Although less energyefficient, halogen lamps were chosen in the first place in order to avoid the presence of these artificial EMFs in the cultures (Vale 2015b).

\section{Statistical treatment}

Non-linear regressions and Student $t$-test statistics were carried out in SigmaPlot ver. 12.0 (Systat Software, Inc.).
A

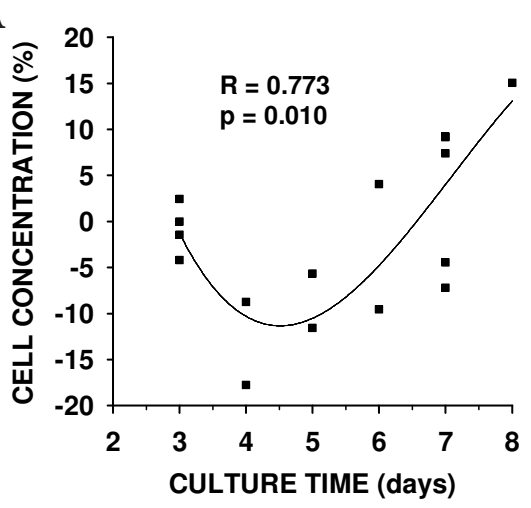

C

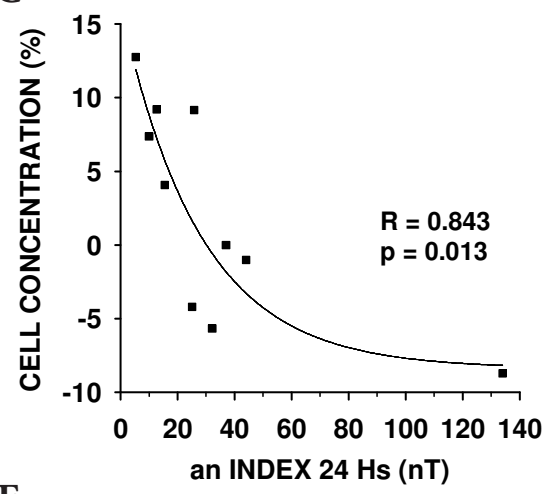

E

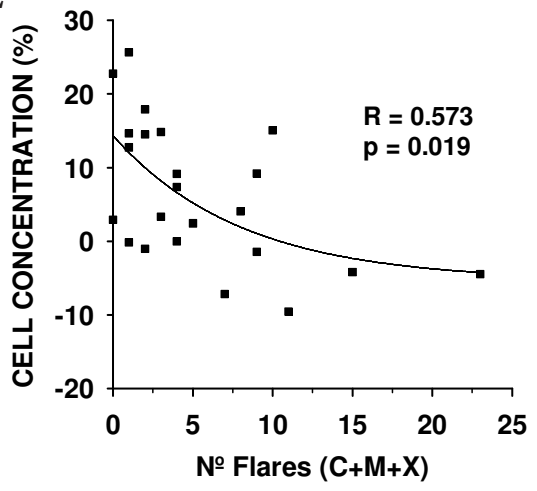

B

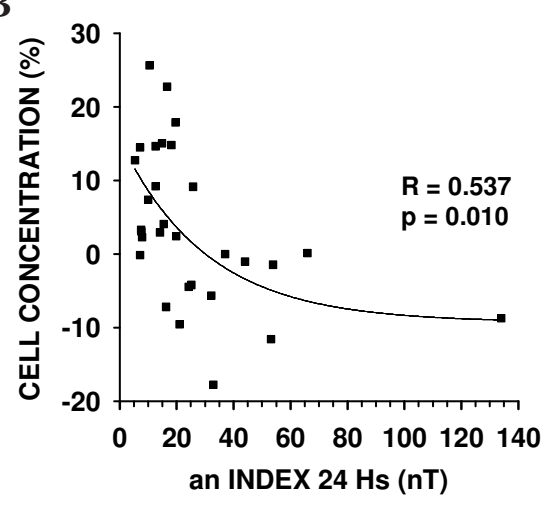

D

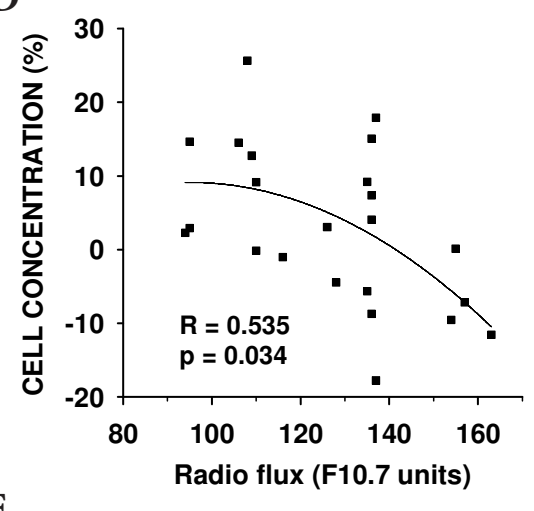

$\mathbf{F}$

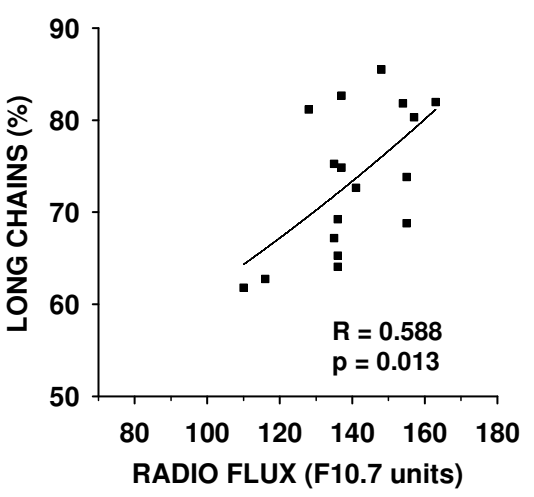

Figure 2. Non-linear regressions for changes in cell concentration in Experiment I versus culture time for flare number $>3(\mathbf{A}, n=16)$; mean an index $24 \mathrm{~h}$ before experiment termination $(\mathbf{B}, n=30)$; cell concentration change for temperature $>26.5^{\circ} \mathrm{C}(\mathrm{C}$, $n=10)$; solar radio flux for culture time $>3$ days $(\mathbf{D}, n=23)$; number of solar flares for culture time equal to 3 or $6-7$ days $(\mathbf{E}, n=23)$. F. Percentage of cells in long chain formation versus radio flux for an Index $>15 \mathrm{nT}$ $(n=15)$. 


\section{Results}

\section{Experiment 1}

During a previous research, conducted to understand MAA's role as multi-functional compounds, a standardized hypo-osmotic shock experiment was devised in order to understand if some MAAs could have an osmolyte role beside the UV photo protection role. Culture aliquots were diluted with ultra pure water provoking a 5 psu salinity drop from 33 to 28 psu. Cells and MAAs concentrations were measured in the culture at the begin and at the end of an eight hour experimental period, that started one hour after entering the circadian light period (12:12 light:dark cycle). Intracellular losses of MAAs were related to their respective initial concentrations (Vale 2016).

Along the repetitions of this experiment it was noted that cell concentration did not always increase when the experimental period terminated indicating that cytolysis could have taken place to a certain extent. Knowing this microalga could be susceptible to solar and/or geomagnetic activity (Vale 2013), changes in cell concentration were then plotted against daily S-GMA parameters (Figs. 1A,B). Decrease in cell concentration was often associated with peaks in S-GMA activity during the trial, while increase in cell concentration was associated with low activity. Due to the relevance of data being obtained, daily repetition of this experiment was prolonged until completing 12 weeks, but no MAA data was collected from the $9^{\text {th }}$ up to the $12^{\text {th }}$ week. A total of 30 repetitions were carried out between April and June 2015 (Figs. 1A-C).

For a more comprehensive understanding of the phenomena, chain composition at the experiment start and changes in cell concentration were correlated with several physiological and physical variables: culture time, initial cell concentration, water temperature, geomagnetic activity, solar radio flux, X-ray flux and X-ray flares. Raw data for these correlations was presented in Figs. S2 and S4a.
The effects of the hypo-osmotic shock in G. catenatum were dependent on culture time (Fig. 2A), and were adjustable to a polynomial curve $(p<0.05)$. The most sensitive days were the $4^{\text {th }}$ and $5^{\text {th }}$ day after media replenishment, with a mean decrease in cell concentration of $-5.3 \%$ and $-5.7 \%$, respectively, contrasting with remaining days where an increase took place (means of $+5.4 \%,+2.4 \%$ and $+9.1 \%$ on days 3, 6 and 7, respectively). Water temperature during these twelve weeks increased progressively from 24.0 up to $27.5^{\circ} \mathrm{C}$ (Fig. 1C). However, no apparent correlation could be discernible between changes in cell concentration and water temperature (Fig. S2c). Changes in concentration also could not be related with initial cell concentration at T0 (Fig. S4a,c).

Changes in cell concentration were inversely related with several S-GMA indexes (Figs. S2e,g,i,k). Reduction in cell concentration followed an exponential decay curve with the increase in the an geomagnetic index for the previous 24 hours prior to experiment termination $(\mathrm{R}=0.537 ; p=0.01)$ (Fig. 2B). The correlation increased at temperatures above $26.5^{\circ} \mathrm{C}: \mathrm{R}=0.843$ (Fig. $2 \mathrm{C}$ ). Correlation of cell concentration with radio flux or X-ray flux could not be fitted to a statistically significant non-linear regression curve, while with X-ray flares followed an exponential decay curve $(p<$ 0.05) (Fig. 2E). However, changes in cell concentration were significantly associated with radio flux for culture time above 3 days $(p<0.05)$ (Fig. 2D).

As G. catenatum seemed to be simultaneously influenced by different physical parameters, non-linear regressions did not always provided the necessary significance for statistical evaluation. Changes in cell concentration were next analyzed according to threshold limits set arbitrarily in S-GMA parameters. Below these limits cell concentration mostly increased, while above these limits cell concentration mostly decreased (Fig. 3A). The highest significance level $(p<0.001)$ was found for a mean of $22 \mathrm{nT}$ in the an Geomagnetic Index (for a 12-hour period) and a mean of 4.0 X-ray flares/ day. In contrast, a significance of only $p<0.05$ was found
A

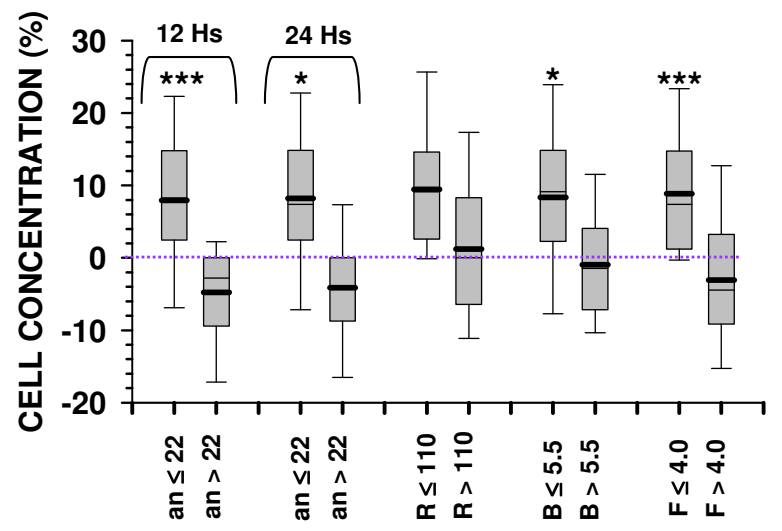

B

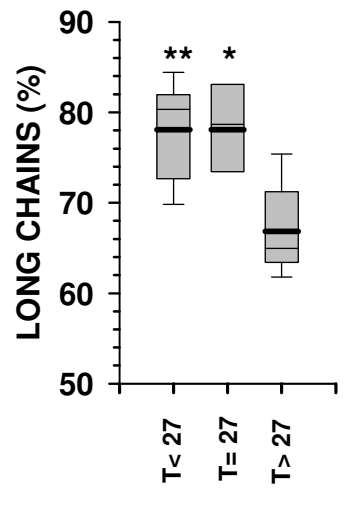

Figure 3. A. Distribution of changes in cell concentration in Experiment 1 accordingly to threshold limits set at $22 \mathrm{nT}$ in an geomagnetic activity $12 \mathrm{~h}$ or $24 \mathrm{~h}$ before termination, at $120 \mathrm{~F} 10.7$ units of radio flux (R), at 5.5 B-level units $\mathrm{X}$-ray flux (B) or at $4 \mathrm{X}$-ray flares/day (F). B. initial percentage of cells in long chain formation accordingly to a threshold in temperature set at $27^{\circ} \mathrm{C}$. Median, $25 \%$ and $75 \%$ percentiles in grey; $5 \%$ and $95 \%$ percentiles in whiskers; mean in bold; ${ }^{*} p<0.05 ;{ }^{* *} p<0.01 ;{ }^{* * *} p<0.001$. 
when using a 24-hour period of geomagnetic activity. This could imply that losses in cell numbers could be related to geomagnetic disturbances that took place close to or even during the course of the hypo-osmotic shock, than prior to this shock. Cell losses were also associated with 5.5 B-level units in X-ray background $(p<0.05)$ but were not statistically significative for radio flux above $110 \mathrm{~F}_{10.7}$ units (Fig. 3A).

For solar activity parameters, data from day-2 was used instead of day- 1 or the mean from these two days. Data from previous days was chosen in first place because for instance measurement of radio flux takes place in British Columbia (Hathaway 2010), a time zone which corresponds to sunset or night at the Lisbon time zone and solar radiation is no longer reaching this geographic area. More important, activities on day-2 were significantly associated with changes in cell concentration, as for example flare activity $(p<0.001)$, but not on day-1 ( $p>0.05)$ (Fig. 4A). This could imply that losses in cell numbers were related to harmful effects from radiation that took place more than 24 hours before the start of Experiment 1 .

Chain composition has been previously associated with different kinds of cellular stresses, such as salinity or light stress (Blackburn et al. 1989; Vale 2015b). Chain composition could provide here information on effects from different physical parameters acting previously to T0 (Fig. S2). At 33 psu cells were mostly grouped in long chains, with 6,8 or more members, rather than in singlets, duplets or quartets. Chain formation along the experimental period could not be related to culture age but was dependent on temperature (Figs. S2b,d). Above $27^{\circ} \mathrm{C}$ a mean level of $67 \%$ of cells in long chain formation was found to be significantly different from $78 \%$ found at $27^{\circ} \mathrm{C}$ or $78 \%$ found below $27^{\circ} \mathrm{C}(p<0.05$ and $p<0.01$, respectively) (Figs. $1 \mathrm{C}$ and $3 \mathrm{~B}$ ).

Concerning S-GMA parameters, no apparent relations could be established (Figs. S2f,h,j,l). However, for radio and $\mathrm{X}$-ray fluxes a cluster of data seemed to be detached from the remaining (marked by ovals in Figs. S2h,j). Data in these clusters corresponded mostly to periods when geomagnetic activity was below a threshold of circa 15 nT (Figs. S2h,j). If data when an geomagnetic Index was below $15 \mathrm{nT}$ were excluded from the correlation, chain formation increased significantly with radio flux $(p<0.02)$, but not with X-ray flux (Fig. 2F). In Experiment 1 the percentage of cells in long chains increased after eight hours from a mean of $75 \%$ in the morning to $82 \%$ in the afternoon, but no relation could be established with any of the physical parameters.

\section{Experiment 2}

A similar experiment was carried out next that started in July 2015 and lasted for 15 consecutive weeks, with a total of 50 repetitions (Figs. 1D, E). The same salinity drop of 5 psu was chosen, but the inoculums were previously cultured at a higher salinity (35 psu) under halogen light. After dilution, cells were immediately transferred to fluorescent lighting and there remained for 24 hours with the same photoperiod. This transfer involved the introduction of extra UV-A stress (Vale 2015a).

In this experiment no reduction in initial cell concentration could be observed (Figs. 1D,E). If cell loss did occur by cytolysis in the first hours, it was masked by the posterior growth. Increase in cell concentration was highest coinciding with reduction in solar and geomagnetic activity (S-GMA; Figs. $1 \mathrm{D}, \mathrm{E})$. Chain composition at the experiment start and changes in cell concentration until experiment termination were correlated with physiological and physical variables as before and raw data for these correlations presented in Figs. S3 and S4b.

In the FLU-room, $88 \%$ of the trials were conducted at a narrow range in temperature between $23.5-25.0^{\circ} \mathrm{C}$. Effects of the hypo-osmotic shock in $G$. catenatum concentration could not be correlated with culture time or temperature, although the highest cellular increases observed took place at day 3 or 4 (Figs. S3a,c). Increase in cell concentration was related to initial concentration (Fig. S4b), with a significant reduction above 2000 cells $/ \mathrm{ml}$ at T0 ( $p<0.05$, Fig. S4c).

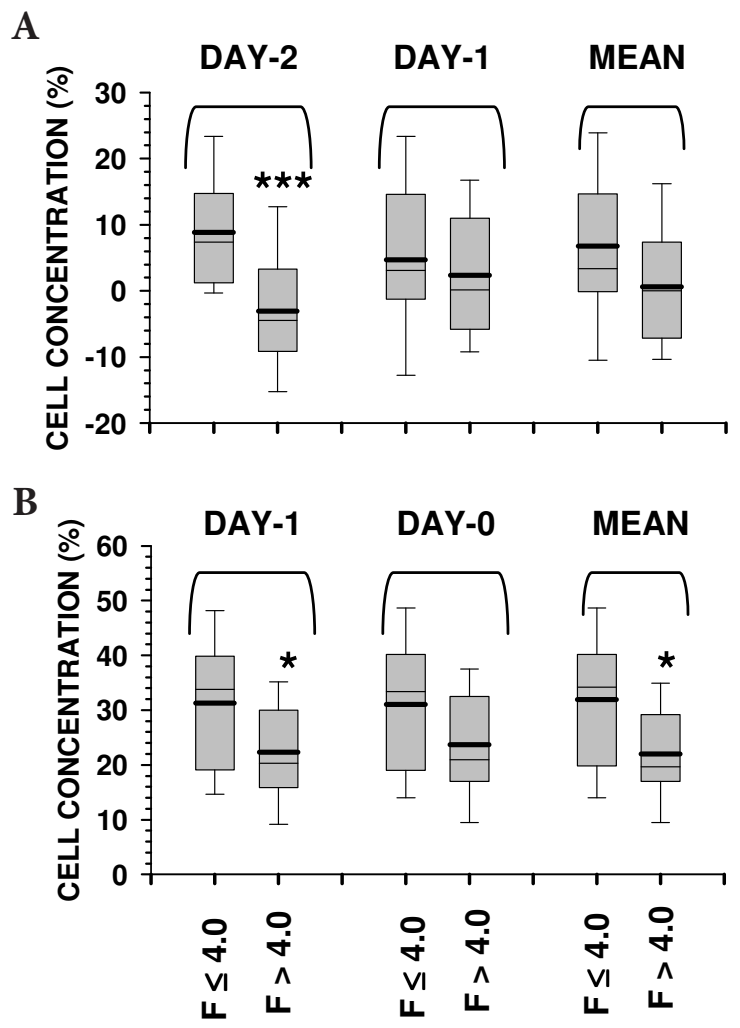

Figure 4. Statistical analysis for changes in cell concentration when flare number (F) was below or above 4 flares/day for day-2, day- 1 or the mean of both days in Experiment 1(A), Experiment 2 (B; selected data for an Index <26 nT). Median, 25\% and 75\% percentiles in grey; $5 \%$ and $95 \%$ percentiles in whiskers; mean in bold; ${ }^{\star} p<0.05 ;{ }^{* * *} p<0.001$. 
Changes in cell concentration were inversely correlated with several S-GMA parameters (Figs. S3e,g,i,k). In order to isolate S-GMA factors from each other, threshold limits were used. Solar indices were studied when an geomagnetic activity was below $26 \mathrm{nT}$ and in the absence of C-or X-flares (Figs. 5A,B). The 24-hour increase in G. catenatum concentration was significantly related with both the radio and the $\mathrm{X}$-ray fluxes $(p=0.002)$. For solar parameters, data from day- 1 was used instead of day- 0 . This was chosen because, for example, flare activity on day- 1 was significantly associated with changes in cell concentration $(p<0.05)$ but not on day-0 (Fig. 4B). This could imply that losses in cell numbers were related to harmful effects from radiation that took place 24 hours before the start of Experiment 2.

Correlation of the an geomagnetic index with cell concentration was studied for a radio flux below $110 \mathrm{~F}_{10.7}$ units or an X-ray flux below 2.5 B-level units (Fig. 6A). In both cases the 24-hour increase in G. catenatum concentration was inversely related with day-0 geomagnetic activity for a threshold level of $26 \mathrm{nT}(p<0.01)$. Mean increase was $>32 \%$ below 26 $\mathrm{nT}$ and $<19 \%$ above $26 \mathrm{nT}$ (Fig. 6A). When an activity was calculated between 48 and 24 hours before termination (day1), no significant correlation was found (Fig. 6A). This could imply that disturbance of cell division could be related to geomagnetic disturbances that took place close to or during the hypo-osmotic shock, than prior to this shock.
At 35 psu cells were grouped in long chains, but the mean percentage was lower than at 33 psu: $64 \%$ versus $75 \%$, respectively (Figs. S2 and S3). Chain formation was not correlated with culture time (Fig. S3b) but was significantly dependent on temperature (Fig. S3d), with a sigmoidal reduction above $27.5^{\circ} \mathrm{C}$ (Fig. $5 \mathrm{C}, p<0.001$ ). Percentage of long chains was directly related with S-MGA activity (Figs. S3f,h,j,l), but this was significant only when cultures grew at the highest temperature range, i.e., above $27.5^{\circ} \mathrm{C}$ (exemplified in Fig. S5). Not all data could be fitted to a non-linear regression curve, as found for the correlation with geomagnetic activity (Fig. 5D). Comparisons resorting to threshold limits were preferred (Fig. 6B). Mean percentage of long chains equalled or surpassed $77 \%$ when geomagnetic activity was above $26 \mathrm{nT}$, radio flux above $117 \mathrm{~F}_{10.7}$ units, X-ray flux above $3.1 \mathrm{~B}$-level units or flare number above 1.0 flares/day $(p<0.002$ in all cases). Above $22 \mathrm{nT}$ the mean percentage attained $73 \%$ but with a lower statistical probability $(p<0.02)$. Below these thresholds the mean percentage of long chains was $53-54 \%$ in all cases.

At $27.5^{\circ} \mathrm{C}$ or below, the mean percentage of long chains was $69 \%$ (Fig. S5a). Above this temperature sub-optimal growing conditions were attained, with a trend towards a high percentage of long chains $(\geq 77 \%)$ with the increase in S-GMA activity, while the opposite occurred during low levels of S-GMA activity: long chain percentage attained
A

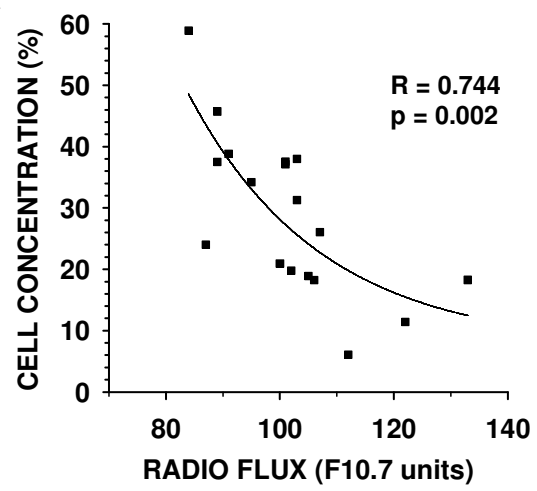

C

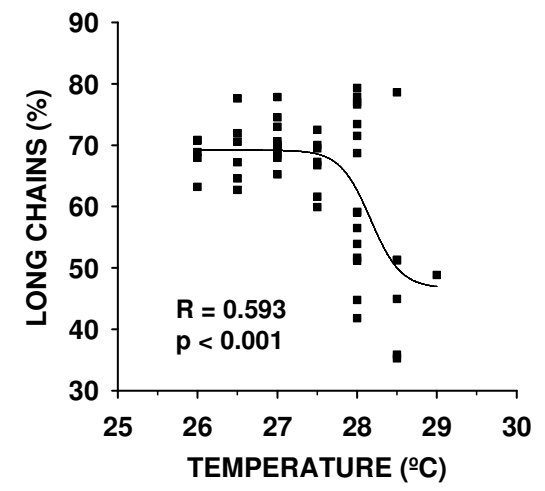

B

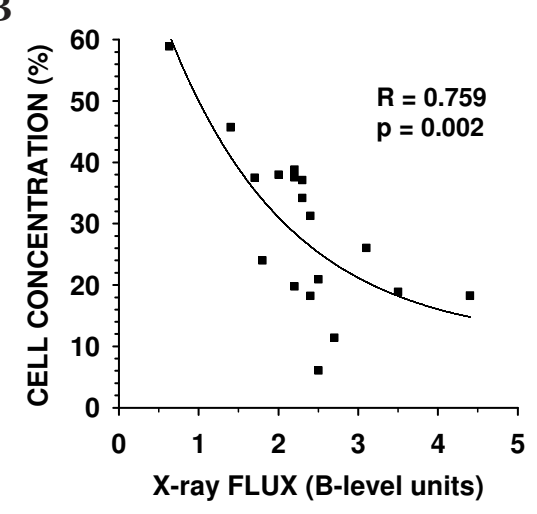

D

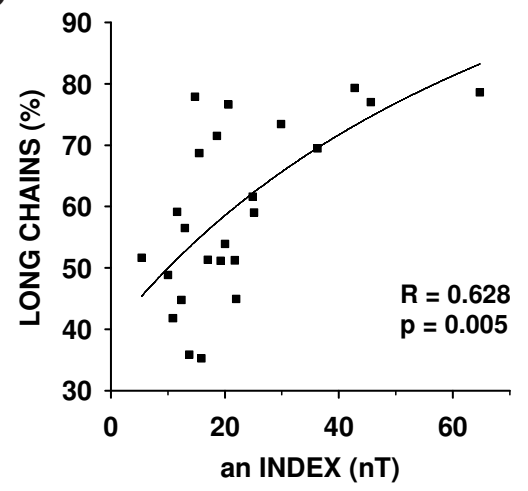

Figure 5. Correlation between changes in cell concentration in Experiment 2 when an Index $<26 \mathrm{nT}$ versus radio flux (A, $n=18$ ); X-ray flux (B, $n=18)$. Percentage of cells in long chain formation versus maximal water temperature $(C, n=50)$ and an Index between July 20th and August 28th when average maximal water temperature was above $27.5^{\circ} \mathrm{C}$ (D, $n=24)$. 
A

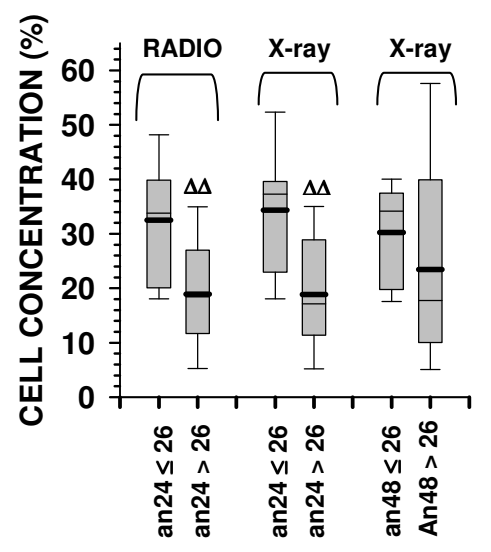

B

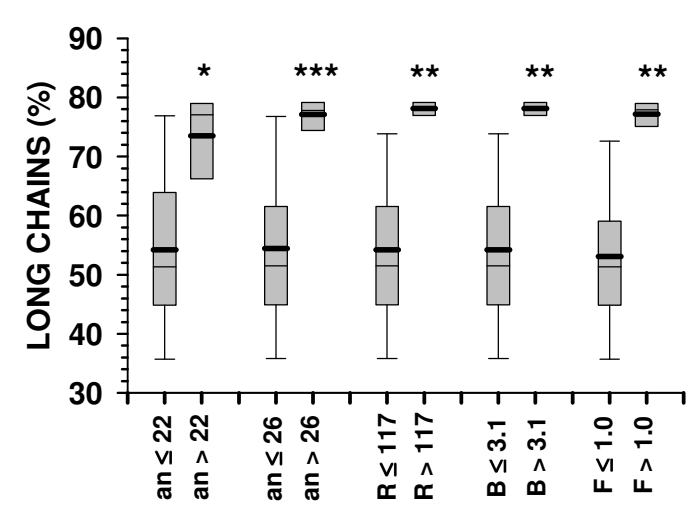

Figure 6. A. Distribution of changes in cell concentration in Experiment 2 according to threshold limits set at 110 F10.7 units in radio flux $(n=36)$ and $2.5 \mathrm{~B}$-Level units in X-ray flux $(n=25)$, and $26 \mathrm{nT}$ in an geomagnetic activity. B. Percentage of cells in long chain formation for water temperature above $27.5^{\circ} \mathrm{C}(n=22)$ according to threshold limits set for geomagnetic activity (an), radio flux (R), B-level X-ray flux (B) or flare number (F). Median, 25\% and 75\% percentiles in grey; $5 \%$ and $95 \%$ percentiles in whiskers; mean in bold. ${ }^{\Delta \Delta} p<0.01,{ }^{*} p<0.02,{ }^{* *} p<0.002,{ }^{* * *} p<0.001$. an 24 , activity from 24 hours before experiment termination; an 48 , activity between 48 and 24 hours before termination.

a minimum of $35 \%$ (Fig. S3 and S5b). Although the gentle homogenization of the stock inoculum culture before each experiment start was not ideal for proper concentration assessment, nevertheless, along the experimental period cell concentration in the inoculum were kept consistently below the mean after surpassing $27.5^{\circ} \mathrm{C}$ (Fig. S6b), also indicating sub-optimal conditions were attained.

\section{Mycosporine-like amino acids in Experiment 1}

Regarding mycosporine-like amino acids determined in Experiment 1, these were also related with S-GMA parameters (Fig. 7). MAAs with anti-oxidant properties, such as palythene, were progressively depressed with the increase of X-ray flux in day-1 $(p<0.01$, Fig. 7A) or geomagnetic
A

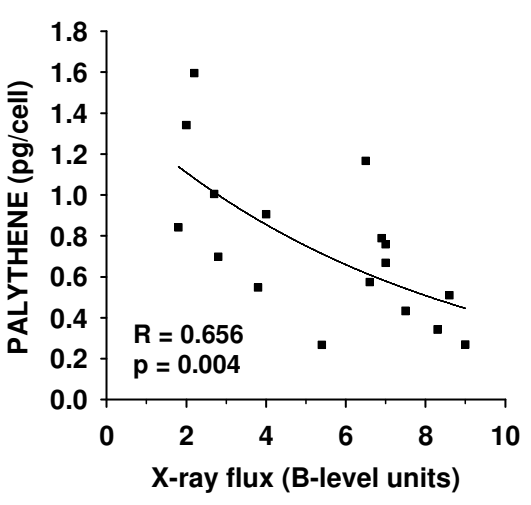

C

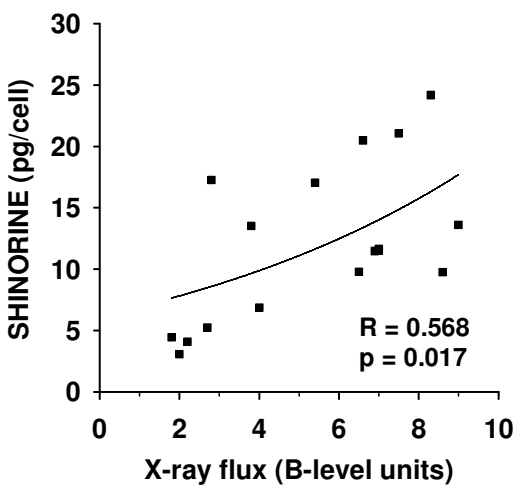

B

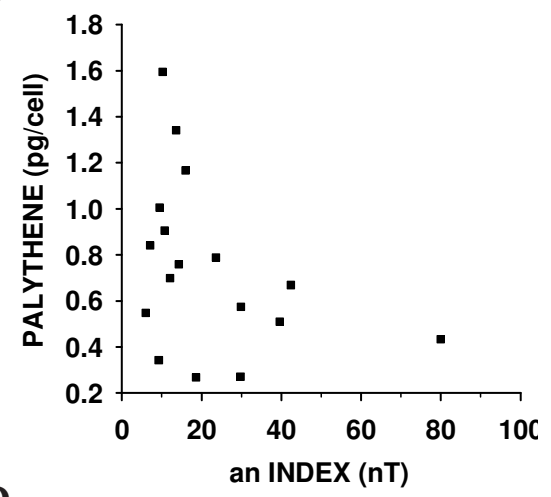

D

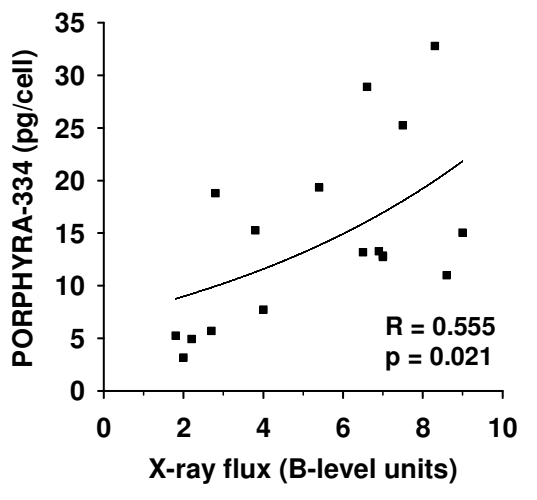

Figure 7. Correlation between X-ray flux or geomagnetic activity and initial concentration of the MAAs: palythene (A and $\mathbf{B})$, shinorine (C) and porphyra-334 (D) determined during Experiment $1(n=17)$. (MAA data originally reported in Vale 2016). 
activity (Fig. 7B). Mean palythene levels were $0.92 \mathrm{pg} / \mathrm{cell}$ when an Index levels in day- 1 were below $18 \mathrm{nT}$, and $0.50 \mathrm{pg} /$ cell when an Index levels were above $18 \mathrm{nT}(p<0.05)$. Mean palythene levels were $0.99 \mathrm{pg} /$ cell when $\mathrm{X}$-rays in day-1 were below 4.0 B-level units and $0.58 \mathrm{pg} /$ cell when X-rays were above 4.0 B-level units $(p<0.01)$.

MAAs with osmolyte properties, such as shinorine and porphyra-334, increased with X-ray flux the previous day $(p<0.05$, Figs. 7C,D) and geomagnetic activity (data not shown). Mean shinorine and porphyra-334 levels were 10.0 and $12.0 \mathrm{pg} / \mathrm{cell}$, respectively when an Index levels the previous day were below $18 \mathrm{nT}$. These levels increased to 15.0 and $17.9 \mathrm{pg} / \mathrm{cell}$ when an Index levels were above $18 \mathrm{nT}$, although results were not statistically significant $(p>0.10)$.

\section{Discussion}

Experiments were carried out in 2015, during the declining phase from the maximum of solar cycle number 24 (NASA 2015). Several rotations of the solar disk were covered: Carrington rotations $n^{\circ} 2163-2165$ in Experiment 1 and n ${ }^{\circ} 2165$ 2169 in Experiment 2 (ALPO 2015). This allowed having wide variations in sunspot area, solar radio flux, $\mathrm{X}$-ray flares and coronal mass ejections (CME) along the experiments. Geomagnetic activity (GMA) is also dependent on the solar cycle. Despite the sun's magnetic pole reversal took place in December 2013 (NASA 2015), GMA tends to remain high during the declining phase of each cycle (Hathaway 2010).

In both hypo-saline shock experiments presented here, cell divisions in G. catenatum were impaired during high SGMA. A maximal threshold of circa 22-26 nT disturbance in GMA was observed in both experiments, above which cell divisions were compromised. Regarding electromagnetic radiation (EMR) at the extremes of the electromagnetic spectrum, levels above 5.5 B-level units of X-ray flux, $4 \mathrm{C}+\mathrm{M}$ flares/day or $110 \mathrm{~F}_{10.7}$ units of radio flux were detrimental. Nevertheless, effects from GMA or EMR were progressive. Threshold limits were used for separating GMA effects from EMR effects and performing statistics. When using MAA data, reduction in antioxidant availability (palythene) was found even at lower thresholds: $18 \mathrm{nT}$ for an Index and 4.0 B-level units for X-ray flux.

S-GMA factors acted in cultures at different time scales. GMA acted during the experimental period of the hypoosmotic shock, while EMR acted one day or more before each experiment's start (Figs. 4 and 6A). This could indicate these factors acted at different phases of the cell cycle and via different mechanisms. During the late light photoperiodic phase, termination of cytokinesis (when cytoplasmic division marks the completion of cell division) was observed and cells remained in long chains before dispersal: a mean increase in $10 \%$ of long chains was observed in Experiment 1 after eight hours along the light period. After the dark photoperiodic phase, cell division was not complete and cells remained as short chains before chain elongation during the light period: a mean reduction in $11 \%$ of long chains was observed in Experiment 2 after 24 hours (harvested 1.5 h past termination of the dark phase).

In Experiment 1 a short period of strong GMA $(<12$ hours) was sufficient to affect cell survival (Fig. 3A). By contrast, increase in EMR was not very effective in the hours preceding the experiment (day-1) but was more effective 24 hours before experiment start (day-2; Fig. 4A). In Experiment 2, increase in GMA before the experiment start also was not effective in disturbing growth (Fig. 6A), while parameters used to determine statistically significant relations with EMR referred to day-1 (or $>24$ hours before experiment ended) (Fig. 4B).

DNA lesions caused by X-rays activate repair mechanisms in the different phases of the cell cycle. Checkpoint-arrested cells resume cell-cycle progression once damage has been repaired, whereas cells with unrepairable DNA lesions undergo permanent cell-cycle arrest or apoptosis (Branzei and Foiani 2008). Dinoflagellates have numerous chromosomes, which remain condensed throughout the cell cycle, but lack histones completely, unlike all the other eukaryotes (Rizzo 2003). Nevertheless, they can pack their huge amounts of DNA into a functional chromatin (de la Espina et al. 2005). Both calcium and magnesium cations play an important role in the neutralization of the negative charge of DNA in the chromosomes and are necessary for the stabilization of dinoflagellate chromosomes (Herzog and Soyer 1983; Strick et al. 2001; Levi-Setti et al. 2008).

$\mathrm{X}$-ray interaction with matter is primarily due to photoelectric effect. Each time a photon ejects an electron - ionizes an atom - this creates free radicals that can damage DNA (Breen and Murphy 1995). Photoelectric absorption is approximately proportional to the atomic number (NIST 2015). The dominant elements ( $, \mathrm{H}, \mathrm{O}$, and $\mathrm{N}$ ) have low $\mathrm{X}$-ray absorption and this increases with phosphorous (abundant in DNA nucleotides) up to calcium (required for chromosome stabilization). But while phosphorous has a K-edge around $2 \mathrm{KeV}$, calcium's $\mathrm{K}$-edge is around $5 \mathrm{KeV}$ (NIST 2015). X-ray flux discussed here is related to measurements in the 100-800 pm range (SPWC 2015), or around $2-10 \mathrm{KeV}$. Not only phosphorous in nucleotides, but also the abundant calcium stabilizing a large number of chromosomes could favour interaction with soft X-rays of different energies.

Radioprotection of DNA can be achieved by administration of an antioxidant, such as melatonin, prior to artificial gamma irradiation (Badr et al. 1999; Assayeda and El-Atyb 2009). However, in data from studies such as these ones, it was also evident that administration of melatonin could lower the rate of micronucleus and structural aberrations in 
non-exposed cells in relation to the non-exposed controls not treated with melatonin (Assayeda and El-Atyb 2009). This could be partially attributed to a radioprotective effect from natural radiation sources. Concentration of palythene, one of the main antioxidizing MAAs known, was depressed in direct proportion with natural X-ray intensity, pointing that fluctuation in exogenous radiation could exert an important oxidizing effect in vitro, which in turn affected DNA integrity.

Because the electromagnetic spectrum is not blocked by the atmosphere in the radiofrequency window (Wilson et al. 2009), it is often used as a better proxy for solar energy output than sunspot number (Hathaway 2010). Because of this transparency window, focus was given previously on the radio flux as having a putative deleterious effect in wild G. catenatum populations (Vale 2013). Correlation with soft $\mathrm{X}$-rays was done here for the first time. The strong correlations found for X-ray flux, and in particular the number of X-ray flares, probably can constitute an even stronger hypothesis to understand why this microalgae does not form dense blooms during sunspot maxima. Other physiological parameters can also be affected by X-ray flux and X-ray flares, such as phototaxis, and they are currently the subject of ongoing research (manuscript in preparation).

Within a solar cycle, radio flux oscillates between minima of $65 \mathrm{~F}_{10.7}$ units and maxima that can attain, depending on the cycle, $>200 \mathrm{~F}_{10.7}$ units (NASA 2015). But X-ray background oscillates by two orders of magnitude between $10^{-7}$ until $10^{-5} \mathrm{~W} / \mathrm{m}^{2}$ (A- up to C-level), while the most commonest $\mathrm{C}$ and $\mathrm{M}$ classes solar flares bursts can attain $>10^{-6}$ and $>10^{-5} \mathrm{~W} / \mathrm{m}^{2}$, respectively. Along solar cycles, C-class flares can fluctuate between $<120 /$ year up to $>2000 /$ year and M-class flares between $<20 /$ year up to $>200$ /year, while the rarest X-class $\left(>10^{-4} \mathrm{~W} / \mathrm{m}^{2}\right)$ can be absent during years of solar minima (Winter and Balasubramaniam 2015).

Accumulation of PSTs produced by $G$. catenatum originates prolonged closures of shellfish harvesting at the western Iberian coast (Vale et al. 2008), and sometimes PSP outbreaks on shellfish gatherers, such as the last one registered in October 2007 (Rodrigues et al. 2014). When comparing for instance S-GMA activity in October 2007, with the same month from a year of maximal activity such as 2014, when no shellfish closures attributed to PSP occurred at the Portuguese coast, large differences in solar indices occurred (NASA 2015). In October 2007, mean daily levels of 0.0 A-level units of X-ray flux, $0.0 \mathrm{C}+\mathrm{M}+\mathrm{X}$ flares and $67.5 \mathrm{~F}_{10.7}$ units of radio flux were recorded. In October 2014, mean daily levels of 1.1 C-level units of X-ray flux, 6.2 C+M+X flares and 153.7 $\mathrm{F}_{10.7}$ units of radio flux were recorded. In October 2014 all these parameters were well above the detrimental thresholds found in-house for cultures of a Portuguese G. catenatum strain. In particular, the mean X-ray flux was two orders of magnitude higher in 2014 than in 2007.
In addition, the attention of several research groups in the field of magnetobiology has focused on the influence of extremely low frequency magnetic fields (ELF-MF) mainly on the calcium metabolism of living cells (Pall 2013). As early as 1985, both Blackman et al. (1985) and Liboff (1985) observed dependence between the frequency of the variable field and the magnitude of the static geomagnetic field. An example of this kind is the bioluminescence of the dinoflagellate, Gonyaulax scrippsae, which is affected by a combination of static and ELF magnetic fields in the $\mu \mathrm{T}$ range (Berden et al. 2001). The induction of multinuclear cells has already been positively correlated with the increase in GMA in the apical meristems of Allium cepa (Nanushyan and Murashev 2003). On the opposite, reduction in the intensity of the static component of the geomagnetic field can stimulate the growth, for instance of Lemna minor (Jan et al. 2015). With such a dependency of calcium for chromosome stabilization, dinoflagellates could be particularly sensitive to disturbance of intracellular calcium distribution, as well as many other cellular processes that are regulated by calcium.

Cells in healthy cultures are actively dividing and can attain long chains. Mean chain length decreases with increased salinity, indicating that salinity can cause a certain degree of stress (Vale 2015b). Concomitantly, MAAs with osmolyte and anti-oxidant properties also increase proportionally with the salinity stress (Vale 2015b). In the present study mean chain length was $75 \%$ at 33 psu and $69 \%$ at 35 psu. Chain length is also reduced at sub-optimal temperatures, both in the high range (this study) and in the low range (unpublished observations). Relation of chain length with temperature has already been found by other authors some time ago (Blackburn et al. 1989).

Chain length can also be related to the circadian rhythm of the cell-cycle. The increase in mean chain length observed on the 8-hour experiment carried out during the light phase could be related to cells ending the division cycle that had already started during the dark phase. The reduction in mean chain length in the 24-hour experiment could be related to cells in chains dispersing during the night to start new 'colonies'. But in artificial culture media nutrients are plentiful and there is no need for immediate population dispersal - cell concentrations in these experiments were only one third of maximal densities achievable with $\mathrm{f} / 2$ media (Vale 2015b). However, increase in chain length could have a completely different meaning other than a fast division without any need for immediate dispersal.

The presence of an elevated percentage of long chains above certain S-GMA threshold might be indicative of an arrest of cell cycle progression caused by S-GMA activity. This does not only translates in growth reduction, but also in other morphological parameters, such as increased attachment in long chains. This kind of increase in mean chain length was particularly notorious at sub-optimal temperatures. 
G. catenatum produces potent neurotoxins (the PSTs), blockers of voltage-gated sodium channels in many animals (Anderson et al. 2004), which might modify potassium channel gating (Wang et al. 2003) and partially block calcium currents (Su et al. 2004). The ecological role of these tetrahydropurine derivatives is not fully understood, nor the adaptation mechanisms for avoiding self-inhibition in the producing organisms. These own mechanisms could in turn create particular sensitivities to alterations in external EMFs. External EMFs can specifically produce excessive activity of the voltage-gated calcium channels (VGCCs) in many cell types suggesting that these may be the direct targets of EMF exposure (reviewed in Pall 2013). Many of these studies implicate specifically the L-type VGCCs such that various L-type calcium channel blockers can block responses to EMF exposure. Although there are other neurotoxins, produced by microalgae, this is the only one known to date to produce several saxitoxin analogues with a hydroxybenzoate moiety (Negri et al. 2003; Vale 2008). This deserves a more in-depth study, as one group of sulphated hydroxybenzoates has been found to increase upon hypo-osmotic shock (unpublished observations).

In the halogen setting, the closest artificial EMFs were dominated by extremely low frequency fields originated from unshielded electric cables from the mains powerline. In the fluorescent setting, additional sources of close artificial EMFs were the electronic ballasts. These emit in the radiofrequency range and might cover the entire kilohertz range (Kvasznicza and Elmer 2006). Equipment emitting high levels of ELF-MF, such as ferromagnetic ballasts, was avoided. Static magnetic fields originating in ferromagnetic materials such as shelves, was also avoided. Despite the presence of a moderate level of artificial time-varying EMFs, nevertheless effects from changes in natural EMFs could be distinctly observed in cultures of G. catenatum. This has been tentatively explained by the ion-cyclotron resonance model, where some of the most biological effective resonance frequencies already found (McLeod et al. 1987; Zhadin et al. 1998; Lisi et al. 2008) were below the 50 $\mathrm{Hz}$ powerline frequency used in Portugal.

Not only metallic ions resonate with ELF-MF, but small organic molecules, such as several amino-acids, have been studied. Combined parallel static and alternating magnetic fields cause a rapid change in the ionic current flowing through an aqueous glutamic acid solution when the alternating field frequency is equal to the cyclotron frequency (Zhadin et al. 1998; Pazur 2004; Comisso et al. 2006; Alberto et al. 2008). Peaks are observed with alternating magnetic field frequency from $1-10 \mathrm{~Hz}$ and the frequency corresponding to the peak is directly proportional to the static magnetic field. Unfortunately there is no data yet for resonance of saxitoxin analogues at frequencies close to the geomagnetic field.
However, the ion-cyclotron resonance model presents some limitations (Binhi 2007). In turn, there is ample evidence that EMFs in their entire frequency spectrum induce increase of oxidative stress and oxygen free radicals in many experimental systems (including plants) (reviewed in Georgiou 2010). In the present research, the concentration of palythene, one of the main antioxidizing MAAs known, was almost halved when the an Geomagnetic Index was above $18 \mathrm{nT}$, pointing that GMA could exert oxidizing effects.

So far there is no clear understanding of the mechanisms geomagnetic activity impacts on living organisms: if it is attributed to slow changes in geomagnetic field intensity or to ultra-low-frequencies. Krylov et al. (2014) ruled out geomagnetic pulsations in the $0.001-5 \mathrm{~Hz}$ range in flax, pea, Daphnia magna and crucian carp.

The human population - amongst a few other mammals - has been mostly studied regarding ELF-MF exposure. A doubling in the incidence for childhood leukemia has been found when living in homes with exposure above $400 \mathrm{nT}$ of 50-60 Hz magnetic fields (Ahlbom et al. 2000) and the International Agency for Research on Cancer (IARC 2002) already classifies power-frequency magnetic fields as a possible human carcinogen (Group 2B). Based on a review of the literature, lowering the public's exposure standards to $100 \mathrm{nT}$ has been advocated to prevent cancer and other health effects (Bioinitiative 2007). Regarding GMA, disturbance in the geomagnetic field above 100-200 nT increase arterial blood pressure in humans (Dimitrova 2004). In rats the depth of the hypothermia was significantly reduced if the ambient geomagnetic activity exceeded $35 \mathrm{nT}$ to $40 \mathrm{nT}$ (Bureau et al. 1996), while mortality in rats with induced limbic lability increased when the $24 \mathrm{~h}$ geomagnetic indices exceeded $20 \mathrm{nT}$ for more than 1 to 2 days (Bureau and Persinger 1992). In the present study, survival of G. catenatum to an abrupt hypo-osmotic shock was compromised above circa $20 \mathrm{nT}$ disturbance in the geomagnetic field.

The hypothesis for the existence of two separate deleterious mechanisms of action, reinforce our previous suspicion that natural occurrence of PSTs derived from G. catenatum can be correlated with both distinct solar EMR and GMA parameters (Vale 2013). GMA also shows a solar cycle dependence, but one that is more complex than seen in sunspot area, radio flux, or flares and CMEs (Hathaway 2010). Geomagnetic variability can be decomposed into two components - one proportional to and in phase with the sunspot cycle (the R, or Relative sunspot number component) and another out of phase with the sunspot cycle (the I, or Interplanetary component). GMA can be a powerful restrictor, not allowing blooms during sunspot minima - such as in 2006 when GMA was increasing during the autumnal window of opportunity - while low activity was coincidental with sporadic blooms outside solar minimum - such as in 2011 or 2012 (Vale 2013, 2014). 
The influence of extraterrestrial forcing on the natural occurrence of this microalga seems to be quite unique, with Iberian populations practically disappearing during solar maxima. Nevertheless, the influence of natural electromagnetic rhythms in life as a whole is gaining more acceptance, and research in chronoastrobiology is increasing (Halberg et al. 2004; Muehsam and Ventura 2014). S-GMA has been found to affect also a wide diversity of multicellular organisms, as diverse as human beings, rats, fruit flies and plants (Héroux 1979; Dimitrova 2004; Izmaylov et al. 2005; Krylov et al. 2014; Shaposhnikov et al. 2014).

Acknowledgements. The results presented in this paper rely on geomagnetic indices calculated and made available by ISGI Collaborating Institutes from data collected at magnetic observatories. We thank the involved national institutes, the INTERMAGNET network and ISGI (isgi.unistra.fr). Appreciation is due to Space Weather Canada (Canada) and NOAA's Space Weather Prediction Center (USA), for usage of solar data. Appreciation is also due to Instituto Hidrográfico (Portugal) for usage of ocean temperature data. Funding for IPMA was obtained from PROMAR (EU 2007-2013 Operational Fisheries Program). M.M. Angelico provided access to the stereo microscope and $\mathrm{M}$. Nogueira to light measuring equipment and also usage of fluorescent lighting material. Comments from two anonymous reviewers were very welcome and useful.

\section{References}

Ahlbom A., Day N., Feychting M., Roman E., Skinner J., Dockerty J., Linet M., McBride M., Michaelis J., Olsen J. H. et al. (2000): A pooled analysis of magnetic fields and childhood leukaemia. Br. J. Cancer 83, 692-698 http://dx.doi.org/10.1054/bjoc.2000.1376

Alberto D., Busso L., Garfagnini R., Giudici P., Gnesi I., Manta F., Piragino G., Callegaro L., Crotti G. (2008): Effects of extremely low-frequency magnetic fields on L-glutamic acid aqueous solutions at 2040 and $60 \mathrm{mT}$ static magnetic fields. Electromagn. Biol. Med. 27, 241-253 http://dx.doi.org/10.1080/15368370802344052

ALPO (2015): http: //alpo-astronomy.org/solar/rotn_nos.html

Anderson P. A. V., Roberts-Misterly J., Greenberg R. M. (2004): The evolution of voltage-gated sodium channels, were algal toxins involved? Harmful Algae 4, 95-107 http://dx.doi.org/10.1016/j.hal.2003.12.007

Assayeda M. E., El-Atyb A. M. A. (2009): Protection of rat chromosomes by melatonin against gamma radiation-induced damage. Mutat. Res. 677, 14-20 http://dx.doi.org/10.1016/j.mrgentox.2009.04.016

Babayev E. S., Allahverdiyeva A. A. (2007): Effects of geomagnetic activity variations on the physiological and psychological state of functionally healthy humans: Some results of Azerbaijani studies. Adv. Space Res. 40, 1941-1951 http://dx.doi.org/10.1016/j.asr.2007.02.099

Badr F. M., El Habit O. H. M., Harraz M. M. (1999): Radioprotective effect of melatonin assessed by measuring chromosomal damage in mitotic and meiotic cells. Mutat. Res. 444, 367-372
http://dx.doi.org/10.1016/S1383-5718(99)00103-5

Berden M., Zrimec A., Jerman I. (2001): New biological detection system for weak ELF magnetic fields and testing of the paramagnetic resonance model (Lednev 1991): Electro Magnetobiol. 20, 27-41

http://dx.doi.org/10.1081/JBC-100103158

Binhi V. N. (2007): A few remarks on ,combined action of DC and AC magnetic fields on ion motion in a macromolecule. Bioelectromagnetics 28, 409-414 http://dx.doi.org/10.1002/bem.20314

Blackburn S. I., Hallegraeff G.M., Bolch C.J. (1989): Vegetative reproduction and sexual life cycle of the toxic dinoflagellate Gymnodinium catenatum from Tasmania Australia. J. Phycol. 25, 577-590 http://dx.doi.org/10.1111/j.1529-8817.1989.tb00264.x

Blackman C. F., Benane S. G., Rabinowitz J., House D. E., Joines W. (1985): A role of the magnetic field in the radiation induced efflux of calcium ions from brain tissue in vitro. Bioelectromagnetics 6, 327-337 http://dx.doi.org/10.1002/bem.2250060402

Bondarenko N. A., Evstafyev V. K. (2006): Eleven- and ten-year basic cycles of Lake Baikal spring phytoplankton conformed to solar activity cycles. Hydrobiologia 568, 19-24 http://dx.doi.org/10.1007/s10750-006-0339-1

Branzei D., Foiani M. (2008): Regulation of DNA repair throughout the cell cycle. Nat. Rev. Mol. Cell Biol. 9, 297-308 http://dx.doi.org/10.1038/nrm2351

Bravo I., Anderson D. M. (1994): The effects of temperature growth medium and darkness on excystment and growth of the toxic dinoflagellate Gymnodinium catenatum from northwest Spain. J. Plankton Res. 16, 513-525 http://dx.doi.org/10.1093/plankt/16.5.513

Breen A. P. Murphy J. A. (1995): Reactions of oxyradicals with DNA. Free Radic. Biol. Med. 18, 1033-1077 http://dx.doi.org/10.1016/0891-5849(94)00209-3

Bureau Y. R. J., Persinger M. A. (1992): Geomagnetic activity and enhanced mortality in rats with acute (epileptic): limbic lability. Int. J. Biometeorol. 36, 226-232 http://dx.doi.org/10.1007/BF02726403

Bureau Y. R. J., Persinger M. A., Parker G. H. (1996): Effect of enhanced geomagnetic activity on hypothermia and mortality in rats. Int. J. Biometeorol. 39, 197-200 http://dx.doi.org/10.1007/BF01221392

Comisso N., Del Giudice E., De Ninno A., Fleischmann M., Giuliani L., Mengoli G., Merlo F., Talpo G. (2006): Dynamics of the ion cyclotron resonance effect on amino acids adsorbed at the interfaces. Bioelectromagnetics 27, 16-25 http://dx.doi.org/10.1002/bem.20171

de la Espina S.M.D Alverca E., Cuadrado A., Franca S. (2005): Organization of the genome and gene expression in a nuclear environment lacking histones and nucleosomes, the amazing dinoflagellates. Eur. J. Cell Biol. 84, 137-149 http://dx.doi.org/10.1016/j.ejcb.2005.01.002

Diffey B. (2015): Solar spectral irradiance and summary outputs using Excel. Photochem. Photobiol. 91, 553-557 http://dx.doi.org/10.1111/php.12422

Dimitrova S., Stoilova I., Cholakov I. (2004): Influence of local geomagnetic storms on arterial blood pressure. Bioelectromagnetics 25, 408-414 
http://dx.doi.org/10.1002/bem.20009

FAO (2004): Marine Biotoxins FAO Food and Nutrition Paper 80. Food and Agriculture Organization of the United Nations Rome.

Galic M. A., Persinger M. A. (2007): Lagged association between geomagnetic activity and diminished nocturnal pain thresholds in mice. Bioelectromagnetics 28, 577-579 http://dx.doi.org/10.1002/bem.20353

Georgiou C. D. (2010): Oxidative stress-induced biological damage by low-level EMFs, mechanism of free radical pair electron spin-polarization and biochemical amplification. Eur. J. Oncol. Library 5, 63-113

Halberg F., Cornélissen G., Regal P., Otsuka K., Wang Z., Katinas G. S., Siegelova J., Homolka P., Prikryl P., Chibisov S. M. et al. (2004): Chronoastrobiology, proposal nine conferences heliogeomagnetics transyears near-weeks near-decades phylogenetic and ontogenetic memories. Biomed. Pharmacother. 58, S150-187 http://dx.doi.org/10.1016/S0753-3322(04)80025-8

Hathaway D. H. (2010): The solar cycle. Living Rev. Solar Phys. 7, 1 http://dx.doi.org/10.12942/lrsp-2010-1

Héroux O. (1979): Circadian and circannual variations in growth and cold resistance of warm acclimated rats and their relationship with the geomagnetic activity. Int. J. Biometeor. 23, 51-62 http://dx.doi.org/10.1007/BF01553376

Herzog M., Soyer M. O. (1983): The native structure of dinoflagellate chromosomes and their stabilization by $\mathrm{Ca} 2+$ and $\mathrm{Mg} 2+$ cations. Eur. J. Cell Biol. 30, 33-41

Hu W., Connell D., Mengersen K., Tong S. (2009): Weather variability sunspots and the blooms of cyanobacteria. Ecohealth 6, 71-78 http://dx.doi.org/10.1007/s10393-009-0223-3

IARC (2002): Monographs on the evaluation of carcinogenic risks to humans, Volume 80. Non-ionizing radiation Part 1, Static and extremely lowfrequency (ELF): electric and magnetic fields. Lyon France, IARC Press

ISGI (2015): http: //isgi.unistra.fr

Izmaylov D. M., Obukhova L. K., Konradov A. A. (2005): Correlations of life-span variation parameters in 128 successive generations of Drosophila melanogaster with changes in atmospheric pressure and geomagnetic activity. Int. J. Biometeorol. 49, 337-344 http://dx.doi.org/10.1007/s00484-004-0243-1

Jan L., Fefer D., Košmelj K., Gaberšcik A., Jerman I. (2015): Geomagnetic and strong static magnetic field effects on growth and chlorophyll a fluorescence in Lemna minor. Bioelectromagnetics 36, 190-203 http://dx.doi.org/10.1002/bem.21898

Jeffrey S. W., MacTavish H. S., Dunlap W. C., Vesk M., Groenewould K. (1999): Occurrence of UVA and UVB-absorbing compounds in 152 species (206 strains): of marine microalgae. Mar. Ecol. Prog. Ser. 189, 35-51 http://dx.doi.org/10.3354/meps189035

Kolesnikov V. G., Dreval N. V., Kamenev Y. E., Korzh V. G. (2009): Influence of some areas of electromagnetic spectrum on reaction of water-plants of the opened reservoirs of Kharkiv area. Fizika zivovo 17, 98-104 (in Russian)

Krylov V. V., Bolotovskaya I. V., Osipova E. A. (2013): The response of European Daphnia magna Straus and Australian Daphnia carinata King to changes in geomagnetic field. Electromagn. Biol. Med. 32, 30-39 http://dx.doi.org/10.3109/15368378.2012.700291

Krylov V. V., Zotov O. D., Klain B. I. et al. (2014): An experimental study of the biological effects of geomagnetic disturbances, The impact of a typical geomagnetic storm and its constituents on plants and animals. J. Atmos. Sol. Terr. Phys. 110-111, 28-36 http://dx.doi.org/10.1016/j.jastp.2014.01.020

Kvasznicza Z., Elmer G. (2006): Radio frequency emissions of public lighting devices. IEEE EPE-PEMC 2006 Portorož Slovenia

Levi-Setti R. Gavrilov K. L., Rizzo P. J. (2008): Divalent cation distribution in dinoflagellate chromosomes imaged by highresolution ion probe mass spectrometry. Eur. J. Cell Biol. 87, 963-976

http://dx.doi.org/10.1016/j.ejcb.2008.06.002

Liboff A. R. (1985): Geomagnetic cyclotron resonance in living cells. Biol. Phys. 9, 99-102 http://dx.doi.org/10.1007/BF01878387

Lisi A., Ledda M., De Carlo F., Foletti A., Giuliani L., D'Emilia E., Grimaldi S. (2008): Calcium ion cyclotron resonance (ICR): transfers information to living systems, effects on human epithelial cell differentiation. Electromagn. Biol. Med. 27, 230-240

Moore C. M., Mills M. M., Arrigo K. R., et al. (2013): Processes and patterns of oceanic nutrient limitation. Nat. Geosci. 6, 701-710

McLeod B. R., Smith S. D., Liboff A. R. (1987): Calcium and potassium cyclotron resonance curves and harmonics in diatoms. J. Bioelectr. 6, 153-168 http://dx.doi.org/10.3109/15368378709027735

Muehsam D., Ventura C. (2014): Life rhythm as a symphony of oscillatory patterns, electromagnetic energy and sound vibration modulates gene expression for biological signaling and healing. Global Adv. Health Med. 3, 40-55 http://dx.doi.org/10.7453/gahmj.2014.008

Nanushyan E., Murashev V. (2003): Induction of multinuclear cells in the apical meristems of Allium cepa by geomagnetic field outrages. Russ. J. Plant Physiol. 50, 522-526 http://dx.doi.org/10.1023/A:1024729008858

NASA 2015. http: //solarscience.msfc.nasa.gov/SunspotCycle.shtml Negri A., Stirling D., Quilliam M., Blackburn S., Bolch C., Burton I., Eaglesham G., Thomas K., Walter J., Willis R. (2003): Three novel hydroxybenzoate saxitoxin analogues isolated from the dinoflagellate Gymnodinium catenatum. Chem. Res. Toxicol. 16, 1029-1033

http://dx.doi.org/10.1021/tx034037j

NIST (2015): http: //www.nist.gov/pml/data/xraycoef/index.cfm

Orr R J. S., Stüken A., Murray S. A., Kjetill J. S. (2013): Evolution and distribution of saxitoxin biosynthesis in dinoflagellates. Mar. Drugs 11, 2814-2828 http://dx.doi.org/10.3390/md11082814

Pall M. L. (2013): Electromagnetic fields act via activation of voltage-gated calcium channels to produce beneficial or adverse effects. J. Cell Mol. Med. 17, 958-965 http://dx.doi.org/10.1111/jcmm.12088

Pazos Y., Moro-o A., Tri-anes J., Doval M., Montero P., Vilarinho M. G., Moita M. T. (2006): Early detection and intensive 
monitoring during an anusual toxic bloom of Gymnodinium catenatum advected into the Galician Rías (NW Spain): In: 12th International Conference on Harmful Algae Programme and Abstracts Copenhagen Denmark p. 259

Pazur A. (2004): Characterisation of weak magnetic field effects in an aqueous glutamic acid solution by nonlinear dielectric spectroscopy and voltammetry. Biomag. Res. Tech. 2, 8 http://dx.doi.org/10.1186/1477-044X-2-8

Pitcher G. C., Figueiras F. G., Hickey B. M., Moita M. T. (2010): The physical oceanography of upwelling systems and the development of harmful algal blooms. Prog. Oceanogr. 85, 5-32 http://dx.doi.org/10.1016/j.pocean.2010.02.002

Rizzo P. J. (2003): Those amazing dinoflagellate chromosomes. Cell Res. 13, 215-217 http://dx.doi.org/10.1038/sj.cr.7290166

Rodrigues S. M., de Carvalho M., Mestre T., Ferreira J. F., Coelho M., Peralta R., Vale P. (2012): Paralytic shellfish poisoning due to ingestion of Gymnodinium catenatum contaminated cockles - Application of the AOAC HPLC Official Method. Toxicon 59, 558-566 http://dx.doi.org/10.1016/j.toxicon.2012.01.004

Rodríguez G. R., Villasante S., Garcia-Negro M. C. (2011): Are red tides affecting economically the commercialization of the Galician (NW Spain) mussel farming? Marine Policy 35, 252-257

http://dx.doi.org/10.1016/j.marpol.2010.08.008

Shaposhnikov D., Revich B., Gurfinkel Y., Naumova E. (2014): The influence of meteorological and geomagnetic factors on acute myocardial infarction and brain stroke in Moscow Russia. Int. J. Biometeorol. 58, 799-808 http://dx.doi.org/10.1007/s00484-013-0660-0

Sinha R. P., Klisch M., Gröniger A., Häder D.-P. (1998): Ultravioletabsorbing/screening substances in cyanobacteria phytoplankton and macroalgae. J. Photochem. Photobiol. B 47, 83-94 http://dx.doi.org/10.1016/S1011-1344(98)00198-5

SPWC 2015. http: //legacy-www.swpc.noaa.gov/index.html

Strick R., Strissel P. L., Gavrilov K., Levi-Setti R. (2001): Cation-chromatin binding as shown by ion microscopy is essential for the structural integrity of chromosomes. J. Cell Biol. 155, 899-910 http://dx.doi.org/10.1083/jcb.200105026

Su Z., Sheets M., Ishida H., Li F., Barry W. H. (2004): Saxitoxin blocks L-Type ICa. J. Pharmacol. Exp. Ther. 308, 324-329 http://dx.doi.org/10.1124/jpet.103.056564

Vale P. (2008): Complex profile of hydrophobic paralytic shellfish poisoning compounds in Gymnodinium catenatum detected by liquid chromatography with fluorescence and mass spectrometry detection. J. Chromatogr. A 1195, 85-93 http://dx.doi.org/10.1016/j.chroma.2008.04.073
Vale P. (2013): Can solar/geomagnetic activity restrict the occurrence of some shellfish poisoning outbreaks? The example of PSP caused by Gymnodinium catenatum at the Atlantic Portuguese coast. Biofizika 58, 554-567 (in Russian) http://dx.doi.org/10.1134/s0006350913040179

Vale P. (2014): Modeling the occurrence of shellfish poisoning outbreaks caused by Gymnodinium catenatum (Dinophyceae): through electromagnetic signal triggering. Biofizika 59, 464-474 (in Russian) http://dx.doi.org/10.1134/s0006350914030257

Vale P. (2015a): Effects of light quality and nutrient availability on accumulation of mycosporine-like amino acids in Gymnodinium catenatum (Dinophyceae). J. Photochem. Photobiol. B 143, 20-29 http://dx.doi.org/10.1016/j.jphotobiol.2014.12.016

Vale P. (2015b): Effects of light and salinity stresses in production of mycosporine-like amino acids by Gymnodinium catenatum (Dinophyceae). Photochem. Photobiol. 91, 1112-1122 http://dx.doi.org/10.1111/php.12488

Vale P. (2016): Can mycosporine-like amino acids act as multifunctional compounds in Gymnodinium catenatum (Dinophyceae)? Photochem. Photobiol. 92, 264-275 http://dx.doi.org/10.1111/php.12561

Vale P., Botelho M. J., Rodrigues S. M., Gomes S. S., Sampayo M. A. M. (2008): Two decades of marine biotoxin monitoring in bivalves from Portugal (1986-2006): a review of exposure assessment. Harmful Algae 7, 11-25 http://dx.doi.org/10.1016/j.hal.2007.05.002

Wang J., Salata J. J., Bennett P. B. (2003): Saxitoxin is a gating modifier of hERG K+ channels. J. Gen. Physiol. 121, 583-598 http://dx.doi.org/10.1085/jgp.200308812

Wilson T. L., Rohlfs K., Hüttemeister S. (2009): Tools of Radio Astronomy. 5th Ed., Astronomy and Astrophysics Library, Springer-Verlag Berlin Heidelberg

Winter L. M., Balasubramaniam K. (2015): Using the maximum $\mathrm{X}$-ray flux ratio and X-ray background to predict solar flare class. Adv. Space Res. 13, 286-297 http://dx.doi.org/10.1002/2015sw001170

Zhadin M. N., Novikov V. V., Barnes F. S., Pergola N. F. (1998): Combined action of static and alternating magnetic fields on ionic current in aqueous glutamic acid solution. Bioelectromagnetics 19, 41-45 http://dx.doi.org/10.1002/(SICI)1521-186X(1998)19:1<41::AID-BEM4>3.0.CO;2-4

Received: February 23, 2016

Final version accepted: May 19, 2016

First published online: November 30, 2016 